\title{
A Review of Domestic Empirical Studies on the Intercultural Perspective in Foreign Language Teaching
}

Keli Liu ${ }^{1}$ Xiaoqiu Fu ${ }^{2 *}$

${ }^{1,2}$ School of Foreign Studies, Yangtze University, Jingzhou, China

Type of Work: Peer-Reviewed

DOl: http://dx.doi.org/10.21013/jems.v15.n4.p6

How to cite this paper:

Liu, Keli., Fu, Xiaoqiu. (2019). A Review of Domestic Empirical Studies on the Intercultural Perspective in Foreign Language Teaching. IRA International Journal of Education and Multidisciplinary Studies (ISSN 2455-2526), 15(4), 148-153.doi: http://dx.doi.org/10.21013/jems.v15.n4.p6

(C) Institute of Research Advances.

This work is licensed under a Creative Commons Attribution-Non Commercial 4.0 International License subject to a proper citation to the publication source of the work.

Disclaimer: The scholarly papers as reviewed and published by the Institute of Research Advances (IRA) are the views and opinions of their respective authors and are not the views or opinions of the IRA. The IRA disclaims of any harm or loss caused due to the published content to any party.

Institute of Research Advances is an institutional publisher member of Publishers International Linking Association Inc. (PILA-CrossRef), USA. The institute is an institutional signatory to the Budapest Open Access Initiative, Hungary advocating the open-access of scientific and scholarly knowledge. The Institute is a registered content provider under Open Access Initiative Protocol for Metadata Harvesting (OAI-PMH).

The journal is indexed \& included in WorldCat Discovery Service (USA), CrossRef Metadata Search (USA), WorldCat (USA), OCLC (USA), Open J-Gate (India), EZB (Germany) Scilit (Switzerland), Airiti (China), Bielefeld Academic Search Engine (BASE) of Bielefeld University, Germany, PKP Index of Simon Fraser University, Canada. 


\begin{abstract}
We reviewed all the empirical studies on the intercultural perspective in foreign language teaching, published between 2008 to 2018, on 6 Chinese major refereed journals of linguistics and foreign language education. 21 articles were identified after three rounds of screening. Each article was analyzed from three dimensions: research content, research participants and methodology. The results indicated that domestic studies were mainly involved in new pedagogical strategy application, instrument or model construction, and culture teaching assessment. Most of the research participants were Chinese university students. Only four studies included teachers or foreign students, one included high school students and one postgraduate. In terms of methodology, we found that Chinese scholars widely adopted a mixed methodology, by using both qualitative and quantitative methods. Finally, the study pointed out some weaknesses of the reviewed articles and put forward several suggestions to promote the foundations on the intercultural perspective in foreign language teaching.
\end{abstract}

Keywords: intercultural foreign language teaching (IFLT); intercultural communication competence; empirical studies

\title{
1. Introduction
}

The continuous development of economic globalization and cultural pluralism has led to increasing intercultural communication. The two sides of communication usually come from different countries or have different cultural backgrounds. In many aspects, there are certain differences, which easily lead to intercultural communication errors. In order to avoid such communication errors as much as possible, it is necessary to improve the intercultural competence of the communicators. At the same time, the cultivation of intercultural competence of college students has become a topic of widespread concern in foreign language education circles at home and abroad (Byram, 2014; Hu, 2013). Combined with China's national conditions and characteristics of disciplines, foreign language education has become the main channel for the cultivation of intercultural communication competence. The high-quality talents of cultural communication ability have become one of the important teaching objectives of college English teaching (Ge \& Wang, 2016), and the college English classroom is an important place to cultivate students' intercultural competence (Yang \& Li, 2017). In this context, foreign language education and teaching fields continue to emerge based on this research, and foreign language education and intercultural education are integrated into the college English curriculum system (Sun, 2016). In order to explore the characteristics and development trends of intercultural foreign language teaching in China, this paper focuses on the analysis of empirical research, trying to find some common points and differences to provide a reference for IFLT.

\section{Literature Review}

As an emerging research field, intercultural competence research in foreign language teaching has shown a rapid trend in recent years. The significance and teaching methods of cross-cultural teaching in foreign language courses have been rich in theoretical research results and related applications ( Byram et al., 2002; Byram, 2008; Davis et al., 2005). And Peng (2008) proposed that in order to be in line with international mainstream research, it is necessary to adopt an empirical research approach and treat intercultural communication research with a scientific attitude. In contrast, there is still a considerable gap between China's intercultural communication research and international mainstream research (Peng, 2005).

$\mathrm{Hu}$ (2005) compared the intercultural communication papers published in Chinese academic journals during the four years from 1999 to 2002 with the papers published by the International Journal of Intercultural Relations in the United States during the same period, and found that empirical research papers dominated in American journals, and less than one percent of intercultural communication papers based on empirical research in Chinese journals. Such a low proportion may be related to the scope of the published publications and the content of the publications, but it still reflects the fact that Chinese researchers should increase their empirical research in this field. In the same year, Peng (2005) conducted a content analysis of 1,109 studies on intercultural communication published in 564 academic journals in China from 1994 to 2003, mainly in accordance with the fields and methods adopted by the institute. Variables are classified. The results show that in this decade, China's intercultural communication research mainly focuses on foreign language teaching and English-led language comparison research, and there are few academic research and applied research, and pointed out that there is a lack of strict scientific research methods in intercultural communication research. In 
order to discern the current trends of intercultural communication research in China and abroad and furthermore provide suggestions for future research, Fan \& Hu (2011) have made an analysis of 368 intercultural communication articles published between 2001 and 2005 in 11 major international and domestic academic journals, among which 203 articles are from 10 major domestic academic journals and 165 ones from the American journal entitled International Journal of Intercultural Relations. Each article is analyzed from two perspectives: the research contents and research methods. The results also show that, in terms of research methods, most studies abroad use empirical research methods, most of which use quantitative research. On the contrary, most of the research in China is non- empirical research, and in a small number of empirical studies, most of them use a mixed research method.

From this, we can see that in the previous domestic intercultural communication-related research, the proportion of empirical articles is small, and the discussion and speculation are mostly, especially after contrasting with international journals, this feature is more obvious. Most of the research is based on all the articles in each journal.

\section{Research Design}

\subsection{Research Question}

Galvan (2004) mentioned that articles appear in journals usually fell into five types: reports of empirical research, theoretical articles, literature review articles, anecdotal reports, and reports on professional practices and standards. Among them, the empirical studies are considered primary sources of information, detailing the methodology used in the research and in-depth descriptions and discussions of the findings. Based on this, the 21 empirical studies of the screening were mainly analyzed from the three dimensions of research content, research participants and methodology.

And this study mainly discusses the following two research questions:

1. What are the main contents of empirical research on intercultural foreign language teaching in China?

2. What are the common methods in domestic empirical studies?

\subsection{Research Subjects}

To further clarify the empirical research results of domestic scholars in intercultural foreign language teaching, this study is based on a catalogue of publications in the foreign language and literature section of the Chinese Social Sciences Citation Index. It is found that some publications such as Chinese translation, modern foreign language, and Chinese foreign language contain less content about this field. Therefore, the research chooses these six Chinese major refereed journals of linguistics and foreign language education as the research subjects: Journal of PLA University of Foreign Languages, Technology Enhanced Foreign Language Education, Foreign Language Learning Theory and Practice, Foreign Language Teaching and Research, Foreign Language World, Foreign Languages and Their Teaching. And with the theme word of "intercultural", three rounds of screening were conducted on 213 articles published in these six publications between 2008 to 2018. First of all, based on the title, screening out those meeting notices, literature review, book review, etc., there are 160 left. Secondly, reading the abstract carefully to clarify the theme of the article and screening out those that are not related to the IFLT, such as textbook analysis and evaluation (Suo, 2015; Zheng, 20012), literature research (Long, 2015), etc., there are 110 articles left. Finally, with the addition of looking through the context, screening out the non-empirical studies, it gets 21 empirical studies.

\section{Data Analysis}

4.1 Research content

Through the analysis of all empirical research, the 21 studies can be divided into three categories: (1) pedagogical strategy; (2) instrument/model construction; (3) teaching assessment and the proportion of each of these three categories is $42.8 \%, 23.9 \%$, and $33.3 \%$. It can be seen that the empirical research content related to IFLT in China mainly focuses on classroom teaching practice and related teaching evaluation. Different scholars actively explore and develop different teaching modes and methods (Huang, 2015; Wang, 2013; Zhang, 2016), analyze, evaluate, and construct new curriculum models and outlines (Qin \& Dai, 2013; Liao \& Li, 2017; Chang \& Zhao, 2010). They are committed to building a measurement scale suitable for domestic development from their national conditions (Huang, 2017; Wu et al., 2013; Zhong et al., 2013) to promote the integration of intercultural competence and foreign language teaching. Wang (2016) also mentioned the formation and development of the teaching objectives of college English intercultural communication ability, changed the single linguistic position of college English teaching, made it realize the change of cultural teaching position, and revolutionized 
the cultural view of college English. Also, it enriched the connotation of the college English curriculum and highlighted its dual nature of instrumentality and humanity.

The results also show that many researchers use computer networks to conduct online communication courses or real-time interactive classes (Zhou \& Bleistin, 2016; Ren \& Liang, 2014; Huang, 2011). As we all know, the Internet has become an important carrier of public information and one of the important tools for people to expand their understanding. It can not only effectively expand the breadth and depth of learning resources, the speed of communication and the wide range of influence are also unmatched by other communication media (Ye et al., 2017), and can attract students' attention and enhance the classroom effect.

\subsection{Research participants}

The results showed that most of the studies selected undergraduate students from different majors in the university as the research participants, and one-third of the studies involved English majors. Liu (2012) proposed that the interlanguage intercultural communication ability should be cultivated as the core competence of compound talents according to the 2000 English Teaching Outline for Colleges and Universities. That is to say, in addition to foreign language knowledge and skills, the ability category of compound talents should also include target culture, local culture, global awareness, international vision, and psychological adjustment ability. These are closely related to the cultivation of intercultural communication ability of college students. Therefore, the choice of college students as the research object is also consistent with the educational goal framework.

Only a few studies involve secondary school (Li, 2015), postgraduate students (Wu et al., 2017), teachers (Zhou \& Bleistin, 2016; Xiao et al., 2010), and combined with foreign students (Wang, 2013; Zhou \& Bleistin, 2016; Huang, 2011; Feng et al., 2015)and almost all of the research is from the perspective of the researcher. There are only two articles based on the learner's perspective. To a certain extent, the effect of investigating the curriculum based on the feedback of learners has certain subjectivity (Huang, 2011).

4.3 Methodology

Looking back at the history of cross-cultural communication, we can see that the influential academic achievements are based on practical research work, and empirical research accounts for a large proportion, both quantitative research and qualitative research $(\mathrm{Hu}, 2005)$. Since mainstream research in international intercultural communication focuses on the communication and cognitive behavior of individuals in an intercultural or intercultural environment, most studies use quantitative methods. According to the qualitative, quantitative and mixed these three classified methods, this study found that in these 21 empirical studies, qualitative and quantitative each accounted for $14.3 \%$, and the mixed method accounted for up to $71.4 \%$. Therefore, it can be found that similar to the results of Hu \& Fan (2011), domestic scholars use quantitative methods or qualitative methods, the proportions are close and low, and most of them commonly used the mixed method. Research instruments include questionnaires, scales, and interviews (Huang, 2015; Liao \& Li, 2017; Xiao et al., 2010), and a small number of reflective journals and reports (Zhang, 2016; Ren \& Liang, 2014). Although the sample sizes of the two studies are different, it can also be shown that, unlike the research methods often used by foreign scholars, domestic scholars should try more quantitative methods in empirical research.

\section{Findings and Discussions}

The study found that the number of empirical studies is less than $10 \%$ of the total number of articles in the journals searched, but it has increased compared to the proportion of empirical studies mentioned in previous scholars' studies. It can be seen from this that the empirical research on IFLT in China is gradually increasing, but the growth rate is still slow. Regarding the research content, the empirical research on IFLT in China mainly focuses on three aspects: pedagogical strategy, instrument/model construction, teaching assessment, and the research institute on pedagogical strategy is the most. For the study participants, only four studies included teachers or foreign students, one included high school students and one postgraduate and some studies focus on students with good English proficiency or English majors. According to the Guidelines on College English Teaching in 2017 (the latest edition), intercultural competence is one of the core contents, which means that the cultivation of intercultural communication competence has become an important part of the college English curriculum. Foreign language teaching has gradually become an important platform and way for colleges and universities to cultivate students' intercultural competence (Liao \& Li, 2017). Therefore, to be comprehensively cultivated, it is necessary to cover different areas of specialization, and select students with different 
levels and educational backgrounds as research objects. In addition, domestic scholars only use quantitative or qualitative research methods, the proportions are close and low, and most of them choose the mixed research methods, which is different from the research methods commonly used by international scholars. In order to be in line with the international community and work together to promote the prosperity and development of IFLT, it is one of the directions that we need to work hard to use quantitative methods for empirical research.

\section{Conclusion}

Through the analysis of 21 empirical research articles, the study analyzes and contrasts the three dimensions of research content, research participants and methodology. It can be seen that domestic scholars' research focuses on pedagogical strategy, which helps to enrich teachers' integration of intercultural diversity in foreign language teaching and provide more effective teaching methods, but the construction of scales is still needed. With the increasing importance of IC skills, future research participants should not only cover various professional fields, but also involve different learning groups, and try to adopt different research methods to enrich the connotation of IFLT.

Also, there are some limitations. For example, the samples are merely from six domestic journals and without comparing them with the international articles. And some articles may not have a clear identity and can be categorized into two types. These should be improved in further studies.

\section{Acknowledgement}

The Authors are thankful for the support of the "Key Teaching Research Project at School-level of Yangtze University in 2018". Project Number: JY2018004.

\section{References}

[1]. Byram, M., Gribkova B., \& Starkey H. Developing the Intercultural Dimension in Language Teaching: A Practical Introduction for Teachers[M]. Strasbourg: Council of Europe, 2002.

[2]. Byram, M. From Foreign Language Education to Education for Intercultural Citizenship Essays and Reflections[M]. Clevedon: Multilingual Matters, 2008.

[3]. Byram, M. Twenty-five years on-from cultural studies to intercultural citizenship[J]. Language, Culture and Curriculum, 2014 (3): 209-225.

[4]. Chang, J. \& Zhao, Y. The Curriculum System of the Integration of Content and Language in the Basic Stage of English Major from the Perspective of Students[J]. Foreign Languages and Their Teaching,2010(01):13-17+73.

[5]. Davis, N.E., Cho, M.I., \& Hagenson, L. Intercultural competence and the role of technology in teacher education[J]. Contemporary Issues in Technology in Teacher Education, 2005 (4), 384-394.

[6]. Feng et al. Cross-cultural Synchronous Computer-Mediated Communication: Negotiation of Meaning and Its Role in Lexical Acquisition among Tertiary Chinese Students [J]. Technology Enhanced Foreign Language Education,2015(02):10-16.

[7]. Ge, C. \& Wang, S. On Cultivation of Intercultural Communicative Competence in College English Teaching[J]. Foreign Languages and Their Teaching,2016(02):79-86+146.

[8]. $\quad \mathrm{Hu}, \mathrm{W}$. On Empirical Research in Intercultural Communication[J]. Foreign Language Teaching and Research,2005(05):323-327+400.

[9]. $\mathrm{Hu}, \mathrm{Y}, \mathrm{Fan}, \mathrm{W}$. An Exploratory Study on Intercultural Communication Research Contents and Methods: A Survey Based on the International and Domestic Journal Papers Published from 2001 to 2005[J]. International Journal of Intercultural Relations, 2011 (5): 554-566.

[10]. Hu, W. How to Position Intercultural Communication Competence in Foreign Language Teaching[J]. Foreign Language World,2013(06):2-8.

[11]. Huang, J. The Study of the Learning Environment of A Synchronous Cross-cultural Learning Program Based on A Survey on Learners' Feedbacks [J]. Foreign Languages and Their Teaching,2011(02):57-61.

[12]. Huang, W. An Empirical Study on Process-oriented Culture Teaching and Intercultural Communication Competence training [J]. Journal of PLA University of Foreign Languages, 2015(01):51-58.

[13]. Huang, W. A Preliminary Study on the Construction of Chinese Intercultural Sensitivity Scale[J]. Foreign Language Learning Theory and Practice,2017(02):92-98.

[14]. Jose, L. Galvan. Writing Literature Reviews: A Guide for Students of the Social and Behavioral Sciences, 2nd edition[M]. Pyrczak Publishing, 2004.

[15]. Li, X. An Empirical Study on the Motivational Regulation Strategy of College Students and Middle School Students[J]. Journal of PLA University of Foreign Languages,2015(01):67-74.

[16]. Liao, H. \& Li, Y. An Empirical Study on College English Curriculum Evaluation and Development of Intercultural Competence[J]. Foreign Languages and Their Teaching,2017(02):18-25+146-147.

[17]. Liu, C. An Educational Objective Framework of interdisciplinary foreign language majors[J]. Foreign Language World,2012(01):10-18. 
[18]. Long, D. Women in the Republic of China in the Mirror-Intercultural Image Identity of American Women Writers[J]. Journal of PLA University of Foreign Languages,2015,38(03):144151.

[19]. Peng, S. Quantitative Analysis Method Commonly Used by International Mainstream Scholars in Intercultural Communication Research[J]. Foreign Language Education,2005(04):23-26.

[20]. Peng, S. International Mainstream of Intercultural Communication Research and Empirical Methods[J]. Foreign Languages in China,2008(05):96-103.

[21]. Qin, L. \& Dai, W. A Study on Intercultural Communication Courses Oriented to Develop Multicultural Awareness[J]. Technology Enhanced Foreign Language Education,2013(06):56$60+65$.

[22]. Ren, S. \& Liang, W. An Empirical Study on the effects of the international telecollaboration course on intercultural communicative competence[J]. Foreign Language World,2014(06):87-94.

[23]. Sun, Y. Foreign Language Education and Intercultural Ability Cultivation[J]. Foreign Languages in China,2016(3):17-22.

[24]. Suo, G., Weng, L., \& Kulich, S. Analysis of Intercultural Communication Textbooks Published in China in the Past Three Decades (1985-2014)[J]. Foreign Language World,2015(03):89-96.

[25]. Wang, L. A Comparative Study of the Small-group Discussion Methods Used by Chinese and British Business Students[J]. Foreign Language Teaching and Research,2013(04):593-605+641.

[26]. Wang, S. Interpretation of key Points on Guidelines on College English Teaching [J]. Foreign Language World,2016(03):2-10.

[27]. Wu et al. The Effects of Short-term Study-abroad Context and Language Proficiency on Intercultural Communication Apprehension and Intercultural Sensitivity[J]. Foreign Languages and Their Teaching,2017(03):89-99+149.

[28]. Wu, W., Fan, W. \& Peng, R. An Analysis of the Assessment Tools for Chinese College Students' Intercultural Communicative Competence[J]. Foreign Language Teaching and Research,2013(04):581-592+641.

[29]. Xiao et al. A Study of the "Chinese Culture Aphasia" in Present English Education in Chinese Higher Education [J]. Foreign Language Learning Theory and Practice,2010(01):39-47.

[30]. Yang, H. \& Li, L. An Action Research on Integration of Intercultural Competence with College English Teaching[J]. Foreign Languages and Their Teaching, 2017(2): 13-21,150.

[31]. Ye, L., Zhang, G., \& Yao, Y. A Study of College English's Flipped Classroom in the Era of "Internet Plus"[J]. Technology Enhanced Foreign Language Education, 2017(03):3-8+21.

[32]. Zhang, W. Applying Production-oriented Approach to College English Classrooms: A Teaching Experiment[J]. Foreign Languages and Their Teaching,2016(02):106-114+147.

[33]. Zheng, X. The Concept and Practice of Intercultural Talent Training with Chinese CharacteristicsEvaluate English Reading Course for Intercultural Perspectives[J]. Foreign Language World,2012(02):35-40.

[34]. Zhong, H., Bai, Q. \& Fan, W. A Pilot Study on the Construction of Self-measurement Scales of Intercultural Communication Competence of Chinese College Students[J]. Foreign Language World,2013(03):47-56.

[35]. Zhou, Y. \& Bleistein, T. Teachers' Online Support in Online Intercultural Communication Between Chinese and American University Students [J]. Technology Enhanced Foreign Language Education,2016(04):45-52. 